\title{
A water-ammonia heat transformer to upgrade
}

\section{low-temperature waste heat.}

Silvia Garone ${ }^{1}$, Tommaso Toppi, Marco Guerra, Mario Motta.

Department of Energy, Politecnico di Milano, 20156 Milano, Italy

\begin{abstract}
A prototype water-ammonia absorption heat transformer has been built and thoroughly tested. Compared to water-salts mixtures, water-ammonia allows operating the machine in a lower temperature range, fostering recover of low-grade heat. Driving temperatures between $60^{\circ}$ $\mathrm{C}$ and $64{ }^{\circ} \mathrm{C}$ were tested, with condenser temperatures of $8{ }^{\circ} \mathrm{C}$ to $16^{\circ} \mathrm{C}$. The unit proved able to operate in a stable, reliable and repeatable way in this working range, achieving gross temperature lifts up to $25{ }^{\circ} \mathrm{C}$ and thermal COPs in the range $0.400-0.475$. Useful effect up to $4.5 \mathrm{~kW}$ was achieved, with electric consumption always below $100 \mathrm{~W}$.
\end{abstract}

\footnotetext{
${ }^{1}$ Corresponding author

e-mail address: silvia.garone@polimi.it
} 


\section{Introduction}

\subsection{Application of a low-temperature heat transformer}

In industries, an average of $50 \%$ of the energy input is rejected into ambient [1], often with energyconsuming processes; one of the main hurdles to recovery being its low temperature. Connolly et al. [2] estimate that waste heat from industries in the European Union alone sums up to approximately $2700 \mathrm{PJ} / y e a r$, about $4 \%$ of the total primary energy supply [3]. In a growing energy demand scenario, the exploitation of a fraction of such low temperature heat has relevant potential to improve the overall efficiency and reduce energy needs, emissions and costs.

The direct use of waste heat with passive technologies (heat exchangers and storages) to pre-heat other processes at lower temperature is the simplest option. Nevertheless, a significant share of waste heat is discharged at very low temperatures $\left(<65^{\circ} \mathrm{C}\right)[4]$. Such waste heat can power very few processes [5]. Even ORC cycles are generally designed to work in a higher temperature range [6], and their efficiency becomes extremely low with such driving temperatures [7].

The alternative to the direct use of waste heat is its upgrade to higher temperature levels.

Vapour compression heat pumps can achieve quite large temperature lifts, with significant consumption of electrical energy. Absorption heat pumps, instead, replace the electrical requirements with a high temperature heat source to achieve their effect. In absorption heat transformers, the temperature increase is achieved by degrading a fraction of the low grade heat itself, thus without the need of a high exergy input, except for an almost negligible electrical consumption.

Besides the upgrading of waste heat from industry for internal reuse, a possible application of a low-temperature absorption heat transformer is in district heating networks, where it could ease waste heat or solar thermal energy recovery. This could be obtained with $p$ sibsle configurations. In the first, the heat transformer could upgrade the temperature of these sources, allowing their integration in conventional district heating networks: those have an average supply 
temperature of $86^{\circ} \mathrm{C}$ in Sweden [8] and between 70 and $120^{\circ} \mathrm{C}$ in Denmark [9], the countries representing the state of art of the technology. Alternatively, in fiture $4^{\text {th }}$ generation lowtemperature networks, a heat transformer could locally increase the temperature for those end users that need it.

Such applications would benefit from the ability of heat transformers to provide larger capacity and higher temperature lift with lower temperature heat sink. Thus, both efficiency and capacity would increase in cold winter days, when the heat demand increases.

\subsection{Existing low-temperature heat transformers}

Purpose of this work is the development of an absorption heat transformer, able to run on waste heat temperatures around $60^{\circ} \mathrm{C}$ and to provide a gross temperature lift of at least $20^{\circ} \mathrm{C}$. Several possible cycle configurations are proposed in literature: double effect heat transformers could provide the best COP [10], while double-stage configurations can achieve larger Gross Temperature Lifts (GTL) with lower COP, as also demonstrated experimentally [11]. Triple stage could allow a further increase of GTL [12]. Nevertheless, the review by Rivera et al. [13] shows how a single stage configuration could provide the best compromise in our case, where only a limited GTL is required.

Actually, built examples of single-stage heat transformers normally work in a higher temperature range. For example, the self-circulating prototype by Abrahamsson et al. used a driving temperature of $90{ }^{\circ} \mathrm{C}$ [14] to achieve a GTL of $30^{\circ} \mathrm{C}$ with no electric energy input, while the prototype studied by Stephan et al. [15] uses steam as input source and obtained absorber temperatures up to $145^{\circ} \mathrm{C}$ with a COP of 0.47-0.49.

Other applications focused on the industrial sector, where process heat is normally needed at temperatures above $100^{\circ} \mathrm{C}$. Ma et al. [16] report the results of an industrial-scale machine: a 5000 $\mathrm{kW}$ heat flow from steam at $98^{\circ} \mathrm{C}$ was able to provide a rubber plant with hot water at $110^{\circ} \mathrm{C}$, with an approximate COP of 0.47. Another industrial scale machine, TRAXX, was designed to upgrade 
waste heat at around $80^{\circ} \mathrm{C}$ [17] up to an average of $130^{\circ} \mathrm{C}$ : the construction of a $100 \mathrm{~kW}$ plant was estimated to have a payback time of less than three years. More recently, Liu et al. [18] also used similar input temperatures to achieve direct steam generation, so again the required absorber temperature is up $124^{\circ} \mathrm{C}$. The authors also obtained good performances (COP between 0.20 and 0.38 ) and tested the applicability of falling film heat exchangers to heat transformers.

In terms of temperature levels, few works deal with input temperatures below $80{ }^{\circ} \mathrm{C}$. The system proposed by Sekar and Saravanan for water distillation [19], obtaining potable water from seawater, operates with input temperatures ranging from $80{ }^{\circ} \mathrm{C}$ to $60{ }^{\circ} \mathrm{C}$ with a $\mathrm{COP}$ of $0.3-0.38$. Barragán et al. [20] presented the experimental investigation on a heat transformer operating with a maximum GTL of $19^{\circ} \mathrm{C}$, with an absorber temperature of $84^{\circ} \mathrm{C}$ and a COP up to 0.45 . While most of existing heat transformers exploit water-lithium bromide as working pair, in [20] water-calcium chloride was used. Although the solubility of calcium chloride in water is not high, it has other desirable characteristics such as low viscosity and high stability. This opens up the discussion on the use of alternative working pairs, which may suit better the low-temperature applications.

\subsection{Working fluid choice}

The existing review works on heat transformers [13] [21] [22] confirm that water-lithium bromide the most investigated couple for heat transformers. Despite that, they also report many studies researching alternative fluids, due to the high corrosiveness, viscosity and crystallization risk in some operating ranges of the water-lithium bromide pair. Improvements can be achieved by adding additives as ethylene glycol [23] or using mixtures of various salts [24] rather than LiBr alone, but none of the proposed alternatives succeeded in solving all the drawbacks. Donellan et al. [21] in particular express the view that research should investigate different and less corrosive working fluids to reduce size, weight and capital cost of the equipment. Initial cost that is one the main factors hindering heat transformers diffusion in industry [25]. 
Rivera et al. [13] highlight how, for single stage heat transformers, the highest COP can be obtained with mixtures using water as a refrigerant, while the highest Gross Temperature Lifts (GTL) can obtained mainly with mixtures using ammonia as a refrigerant. This is also confirmed by a theoretical comparison, indicating that the $\mathrm{H}_{2} \mathrm{O}-\mathrm{LiBr}$ couple can achieve slightly better performances than water-ammonia $\mathrm{H}_{2} \mathrm{O}-\mathrm{NH}_{3}$ [26]. Nevertheless, water-ammonia should be reconsidered for low temperature applications: in such a field, GTL can be more relevant than COP alone, while crystallization can be a serious issue for low condensing temperatures.

Moreover, at low temperatures the traditional drawbacks associated with the water-ammonia pair, i.e. the need for rectification and the high pressure involved, are far less impacting. Rectification is necessary to reduce the water content in the refrigerant vapour, but it reduces the cycle performances. In heat transformers driven by low-grade heat, the equilibrium concentration of the vapour is high enough (>99\%) to make rectification unnecessary. Moreover, at low temperature, pressures are fully within industrial standards (not higher than 25 bars in our range), with the plus of removing sub-atmospheric operation and the risk of crystallization associated with water-lithium bromide.

Also, corrosion is less critical in ammonia-water systems than with water-lithium bromide, for two reasons. The first is the lower corrosiveness of the mixture itself, especially at temperatures below $100-120{ }^{\circ} \mathrm{C}$. The second is that, given the relatively high operating pressures, machines are less susceptible to performance degradation due to non-condensable gases [27], which is the main pitfall associated with corrosion [28].

For this reason, simulation of single stage water-ammonia cycles in a low temperature range were carried out in the past, with Best et al. even providing some thermodynamic design data for such machines [29]. Nevertheless, to the extent of the authors' knowledge, no experimental studies of water-ammonia heat transformers are available in literature. This paper reports the construction and experimental assessment of such a prototype: we firstly relate on its design and testing to assess 
stability. Once consistent operation is proven, we present the results of tests for various temperature levels, analysing them on a p-T-X diagram to explain the main machine trends. Finally, we compared overall results to those of already reported prototypes.

\section{Prototype description}

\subsection{Cycle concept}

We built a machine based on the cycle configuration represented in Figure 1. It is a single-stage cycle with two internal heat recoveries: in addition to the solution heat exchanger (SHX) a second recovery on the refrigerant circuit is performed: a refrigerant heat exchanger (RHE) preheats the subcooled liquid at the pump outlet using the condensing vapour coming from the generator, to ease the load on the evaporator.

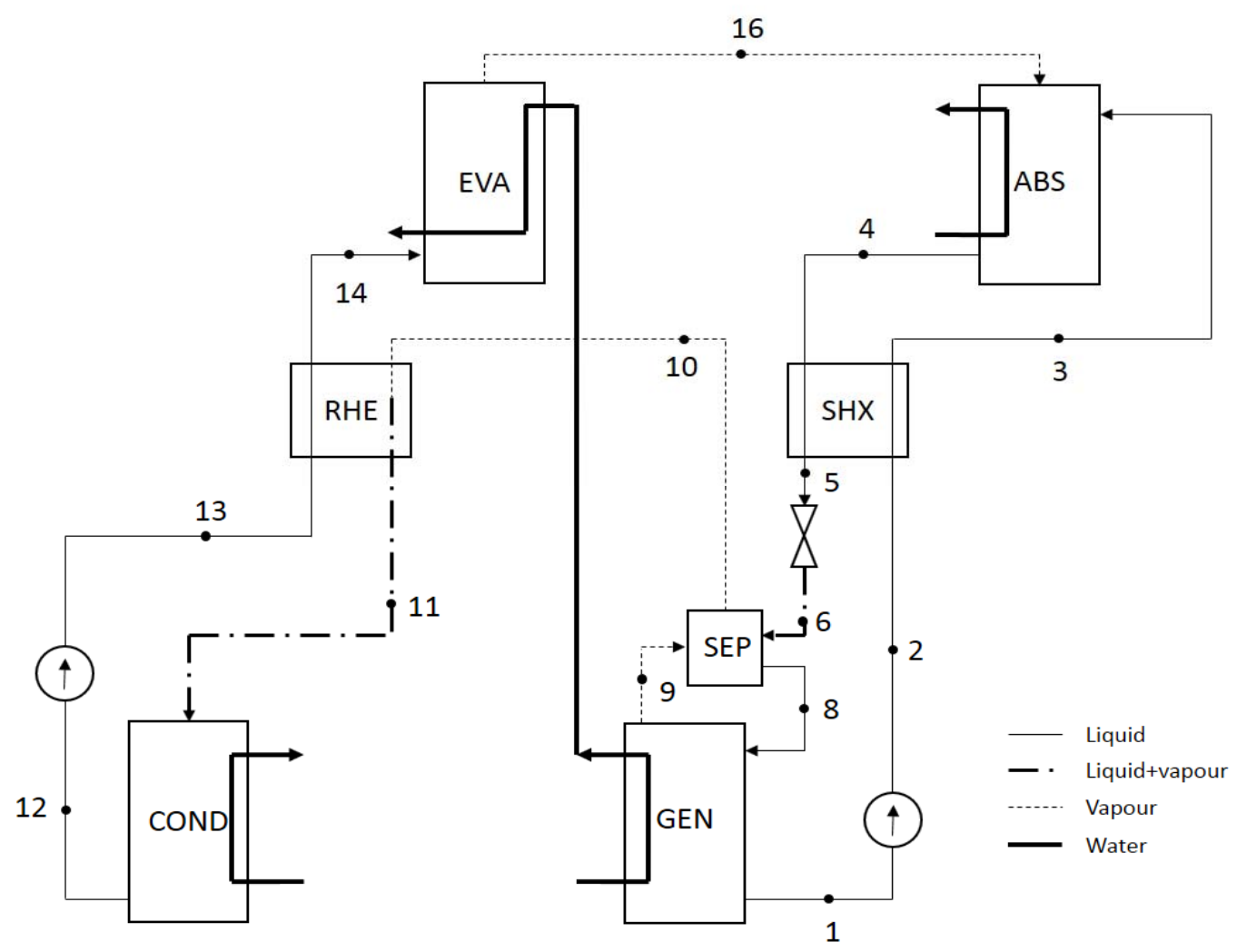

Figure 1: cycle scheme 
With the generator at low pressure, there is no need for a rectifier, but a liquid/vapour separator is used to avoid foam dragging into the vapour flow [30]. The solution is typically two-phase at restrictor outlet, and is routed, together with the generator outlet, towards the separator. The vapour outlet is conveyed to the refrigerant circuit, while the liquid is sent to the generator.

The same external heat source powers both the generator and evaporator, with a series configuration: hot water flows first through the generator and then to the evaporator.

\subsection{Machine features}

As shown in Figure 2, the machine is built as a small-scale prototype: the heat exchangers are designed to cope with a maximum of $12 \mathrm{~kW}$ total thermal input at generator and evaporator. All the external heat exchangers are water-sourced.

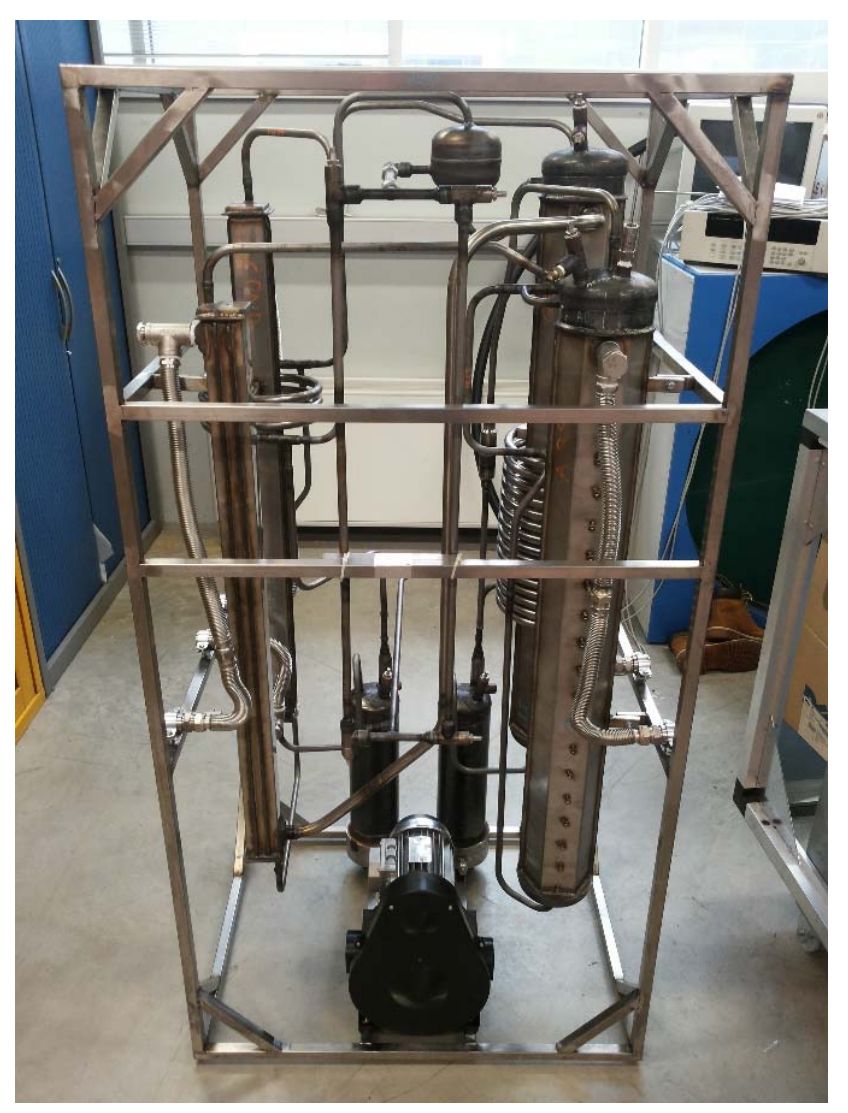

Figure 2: prototype before insulation and sensors installation 
Evaporator and condenser are two symmetrical flow boiling heat exchangers, with vertical flow and shell and tube configuration. In the condenser, the refrigerant vapour enters the inner pipes from the top and the condensate is collected at the bottom, while in the evaporator the liquid refrigerant enters the shell from the bottom. The external fluid is in both cases flowing counter-current. The condenser cooling fluid is brine for a wider testing range, while water flows in the evaporator.

The generator is a vertical falling-film heat exchanger: the heating water providing the thermal energy for the process flows upward in the outer shell. The rich solution enters from the top, where a liquid distributor divides the stream among the tubes and makes it flow downward on their inner surface as a thin liquid film. As it is heated up by water, the rich liquid solution releases refrigerant vapour, which naturally flows upward and exits the generator from the top. The poor solution is collected at the bottom, where the liquid outlet is placed.

The absorber is an identically built heat exchanger with the same sizes, but different flows disposition: the refrigerant vapour enters from the top, as well as the poor solution, which is distributed inside the tubes. As the liquid flows down, it is enriched by the absorbed refrigerant and exits from the bottom. Water flows upward and it is progressively heated up by the exothermic process in counter-current mode.

The two internal heat exchangers (SHX and RHE) are both tube in tube heat exchangers with horizontal flow. They are coiled respectively around the generator and condenser. The outer fluid is rich solution in the SHX and the subcooled refrigerant coming from the pump in the RHE. The solution heat exchanger has a larger surface, since the expected heat duties are about 5-10 times larger than in the refrigerant heat exchanger.

Carbon steel and stainless steel were used for piping and heat exchangers. While commercial waterammonia machines normally employ corrosion inhibitors [31], we didn't deem them necessary in a prototype, especially if working at low temperature $\left(<100^{\circ} \mathrm{C}\right)$.

The machine only has one restrictor. We choose a plate-orifice type with multiple disks. 
The two pumps are oil-driven membrane pumps, both driven by the same inverter-controlled electric motor.

A relevant component is the liquid vapour separator, represented in Figure 3: it is made of a small vertical tank divided by an horizontal porous surface: the upper section is packed with pall rings, while the bottom section is hollow. The streams coming both from the restrictor and the generator enter the separator at the bottom of the upper section. Liquid is collected in the hollow space at the bottom, from where it is sent into the generator. The vapour outlet is placed on top. The separation is only mechanical, without external heating or cooling. This design was chosen after the first version, a smaller hollow tank to slow down the two-phase mixture coming from the restrictor, proved insufficient in preliminary tests: results suggested that a consistent amount of water was present into the refrigerant circuit.

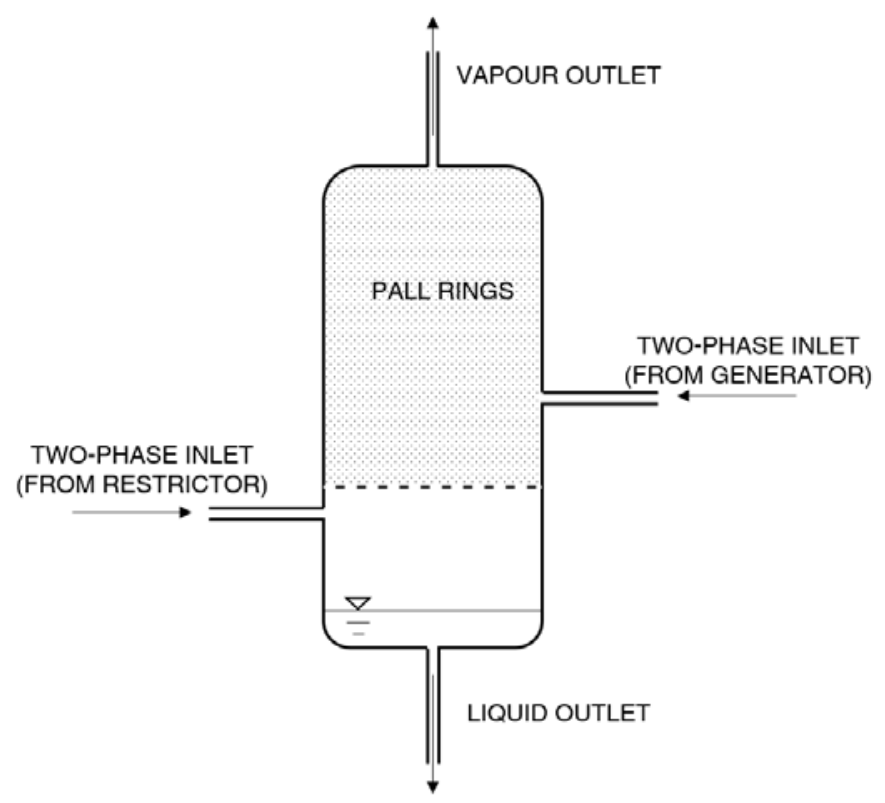

Figure 3: liquid-vapour separator

The prototype is supported by an external structure of $1600 \times 800 \times 600 \mathrm{~mm}$, for a total weight of $110 \mathrm{~kg}$. The final size could have been sensibly smaller, but we choose to keep components widely spaced to ease maintenance operation or modifications. 


\subsection{Measuring equipment}

As shown in Figure 4, the prototype was tested in a calorimeter able to provide three different water or brine (used for the condenser) flows at set temperature and flow rate with a stability of $\pm 0.05{ }^{\circ} \mathrm{C}$ and \pm 10 l/h respectively.

The probes used for each variable are reported in Table 1 together with the overall uncertainty associated with the measure. This is obtained as combined uncertainty of the sensor, the data acquisition chain and signal digitalization.

Temperatures are measured by PT100 thermoresistances, while flow rates by magnetic flowmeters. The resulting uncertainty on exchanged thermal power is always below $5 \%$, usually under $3.5 \%$. The temperature influence on the water properties (density and specific heat capacity) is considered when calculating the heat duties based on volumetric flow rate and temperature difference. A wattmeter measures the electric consumption of the two pumps together.

The machine is equipped with thermocouples (T type), in all cycle points marked in Figure 1 . The thermocouples are insulated to minimize heat transfer towards the environment and improve the accuracy of the measurement. Capacitive pressures transducers provide generator, condenser and absorber pressure. A Coriolis flowmeter is mounted before restrictor inlet (cycle point 6) to measure mass flow rate and density. The density measurement, coupled with temperature, allows to calculate the concentration of the rich solution. Pressure is also a necessary parameter and it is assumed to be the same as in the absorber. The combined uncertainty of the calculated concentration is $3 \%$, which is enough for a first, in-line assessment.

Table 1: measure uncertainties. Percentages refer to the read value

\begin{tabular}{llll}
\hline Quantity & Meter & Range & Uncertainty \\
\hline$T w_{\text {in,COND }}$ & Pt100 & $0 \div 15^{\circ} \mathrm{C}$ & $\pm 0.10^{\circ} \mathrm{C}$ \\
$\Delta T w_{C O N D}$ & Pt100 & $5 \div 25^{\circ} \mathrm{C}$ & $\pm 0.15^{\circ} \mathrm{C}$ \\
$\dot{V} w_{C O N D}$ & magnetic flow meter & $0.6 \div 1.0 \mathrm{~m}^{3} / \mathrm{h}$ & $1.0 \%$
\end{tabular}




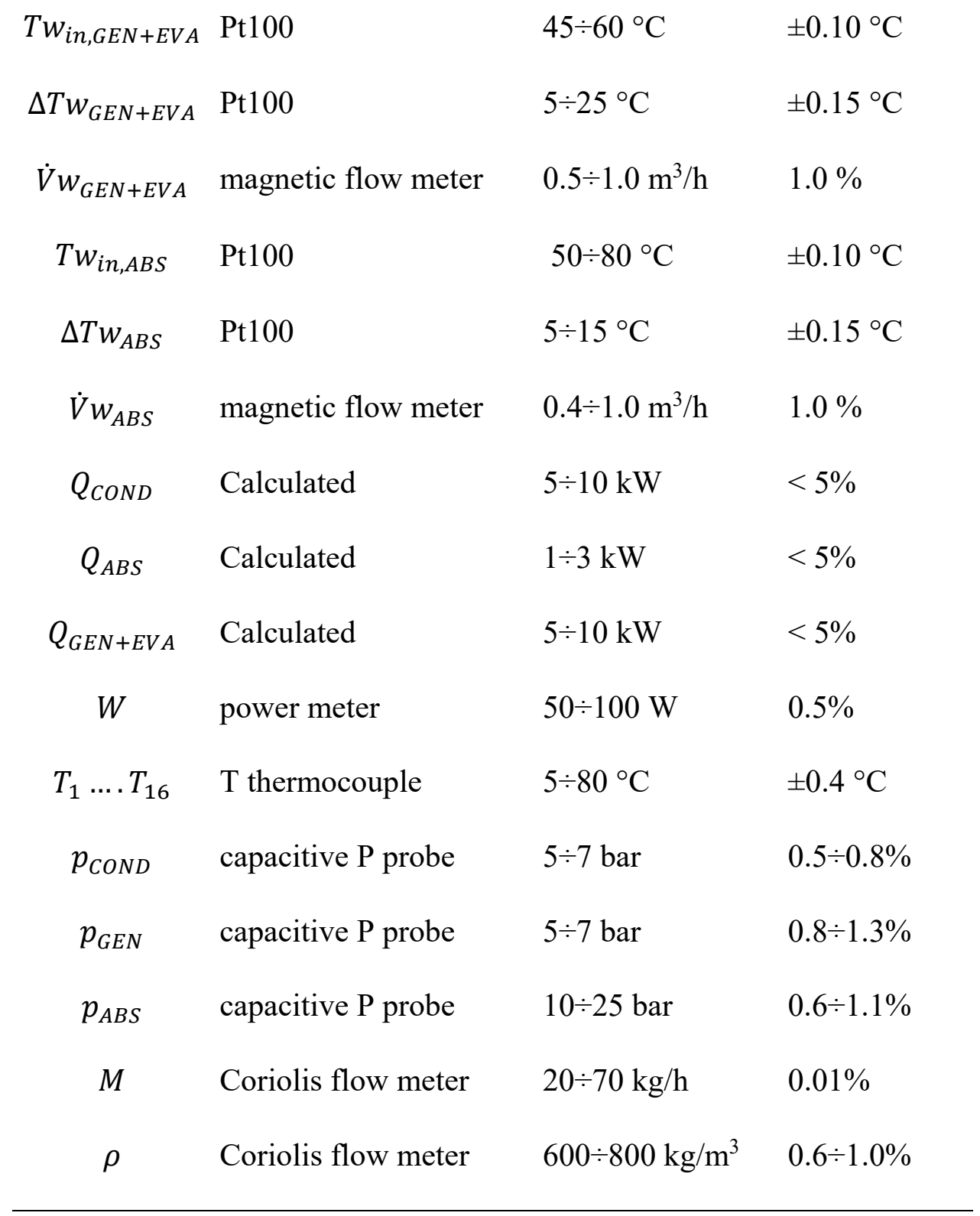

Data was recorded with $0.5 \mathrm{~Hz}$ frequency by two separate Labview ${ }^{\circledR}$ software: the control system of the calorimeter uses a NI PXI as input/output device and records all external flows data, as well as controlling them. Another application, designed for the machine, uses an Agilent 34980A multifunction switch/measure unit and records all cycle points and controls the pump inverter speed. Data is then synchronized and merged. 


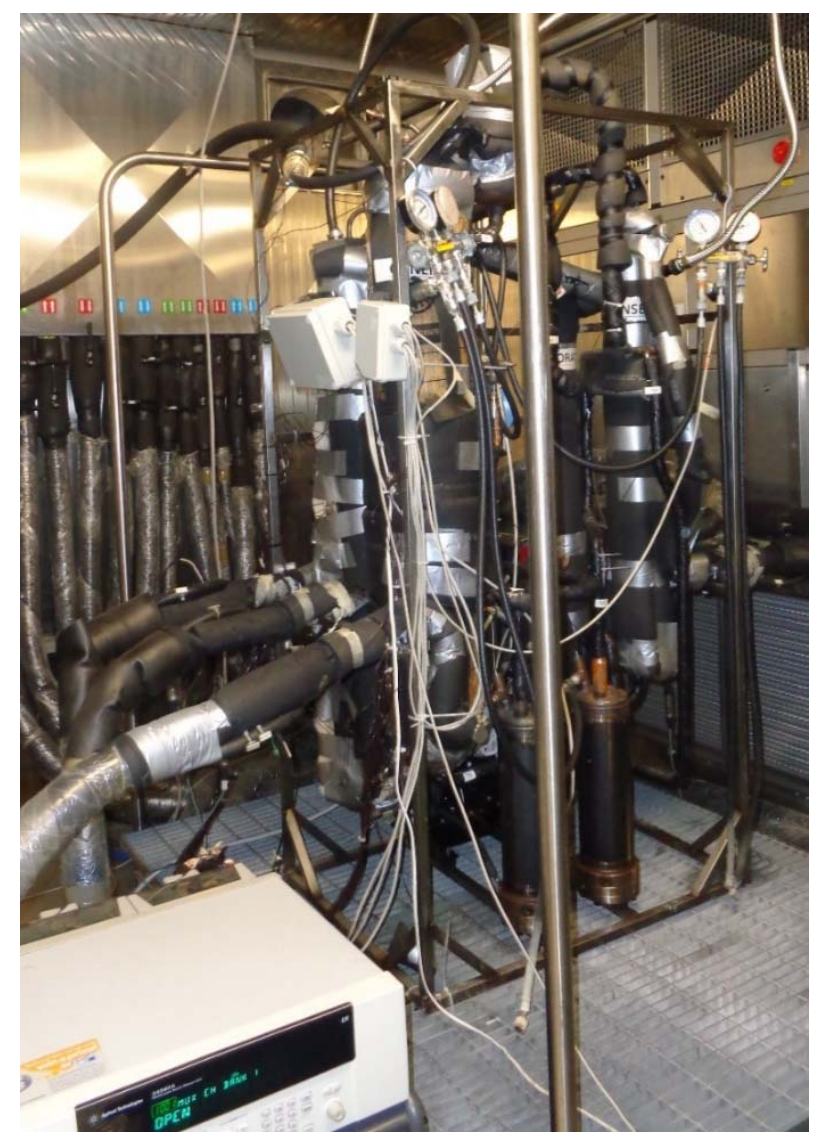

Figure 4: prototype under testing

\section{Testing procedure}

Throughout the whole testing campaign, the same flow rates were used for the hydraulic circuits: $0.6 \mathrm{~m}^{3} / \mathrm{h}$ for the condenser (brine with $40 \%$ glycol was used), $1 \mathrm{~m}^{3} / \mathrm{h}$ for the input circuit serving generator and evaporator, and $0.5 \mathrm{~m}^{3} / \mathrm{h}$ for the absorber water circuit. The values were chosen to have similar temperature differences over all the circuits. The cycle pumps speed was also kept constant for all tests, with the electric motor rotating at $40 \mathrm{~Hz}$.

The data acquisition started after 5 minutes of stable operation and lasted for at least 10 minutes.

The conditions were considered stable when:

- The water and brine supply temperatures read values were within $0.1{ }^{\circ} \mathrm{C}$ of the set value;

- The mass flow rates of water and brine were within $0.01 \mathrm{~m}^{3} / \mathrm{h}$ of the set value;

- The one-minute average of the heat duty at the absorber was within $2.5 \%$ of the mean value over the whole data acquisition period. 
The hydraulic circuits temperatures were chosen to provide a complete mapping of the machine operating trends with the three temperature levels, as summarized in Table 2. A version of the machine with fixed charge was tested under various combinations of those temperature levels, for a total of 80 data points.

The tested $T w_{i n, G E N+E V A}$ levels were chosen in accord with the purpose of the machine to exploit waste heat at temperature lower than $65^{\circ} \mathrm{C}$. Nevertheless, temperatures lower than $60{ }^{\circ} \mathrm{C}$ were not investigated due to the need to avoid a two-phase flow to establish in the SHX. Such an issue is to be solved by re-designing an SHX with lower pressure drop on the rich solution side.

Larger ranges were explored for $T w_{i n, A B S}$ and $T w_{i n, C O N D}$, to identify the main trends in the machine behaviour. Absorber temperatures lower than $70{ }^{\circ} \mathrm{C}$ were not considered significant because of the limited gross temperature lifts involved. On the other hand, an upper boundary was set by the nonpressurized water circuits of the calorimeter, which required water at absorber outlet, as well as in all the auxiliary tanks, to stay below $100^{\circ} \mathrm{C}$.

Compared to the potential winter temperatures of water or air in mid-European climate, higher condenser temperatures were selected for two reasons: to simulate an air-cooled condenser with reasonable temperature differences towards the environment and to explore the machine potential in less favourable conditions, after it had proved able to behave well with lower condensing temperatures.

Table 2: tested inlet temperature levels of the three hydraulic circuits

\begin{tabular}{ccc}
\hline$T w_{\text {in,COND }}$ & $T w_{\text {in,GEN }+E V A}$ & $T w_{\text {in,ABS }}$ \\
\hline $8^{\circ} \mathrm{C}$ & $60^{\circ} \mathrm{C}$ & $70^{\circ} \mathrm{C}$ \\
$10^{\circ} \mathrm{C}$ & $62^{\circ} \mathrm{C}$ & $72^{\circ} \mathrm{C}$ \\
$12^{\circ} \mathrm{C}$ & $64^{\circ} \mathrm{C}$ & $74^{\circ} \mathrm{C}$
\end{tabular}




\section{Verification of the machine operation}

\subsection{Stability}

The machine is able to provide useful effect in a consistent and stable way. Figure 5 reports the trend of the most significant parameters of the cycle during its continuous operation for one hour in a representative test. Graph a) shows the two pressure levels, mass flow rate of the rich solution as well as fluid temperatures at:

- Absorber outlet (T4), rich solution;

- Restrictor outlet (T6);

- Generator vapour outlet (T9);

- Condenser outlet (T12);

- Evaporator outlet (T16)

While graph b) reports the main external parameters: inlet and outlet temperature of the hydraulic circuits and calculated exchanged power.

All cycle and water temperatures are within a maximum standard deviation of $0.1{ }^{\circ} \mathrm{C}$, with the exception of T5. Anyway, all temperature fluctuation from the mean never exceed $0.4{ }^{\circ} \mathrm{C}$.

The standard deviation is $0.4 \mathrm{~kg} / \mathrm{h}$ for the solution flow rate, lower than 0.05 bar for pressure and of $80 \mathrm{~W}$ for the exchanged power of the hydraulic circuits. Moreover, the average value of all exchanged heat duties over five minutes always differs by less than $0.5 \%$ from the average on the following five minutes.

A limited vibration of about $5 \%$ can be noted in $Q_{G E N+E V A}$. The heat duty fluctuation takes place in the evaporator and is induced by small variations of the high pressure, which can be explained with the random formation of intermittent flow patterns (e.g. plug flow) in the absorber pipes. 

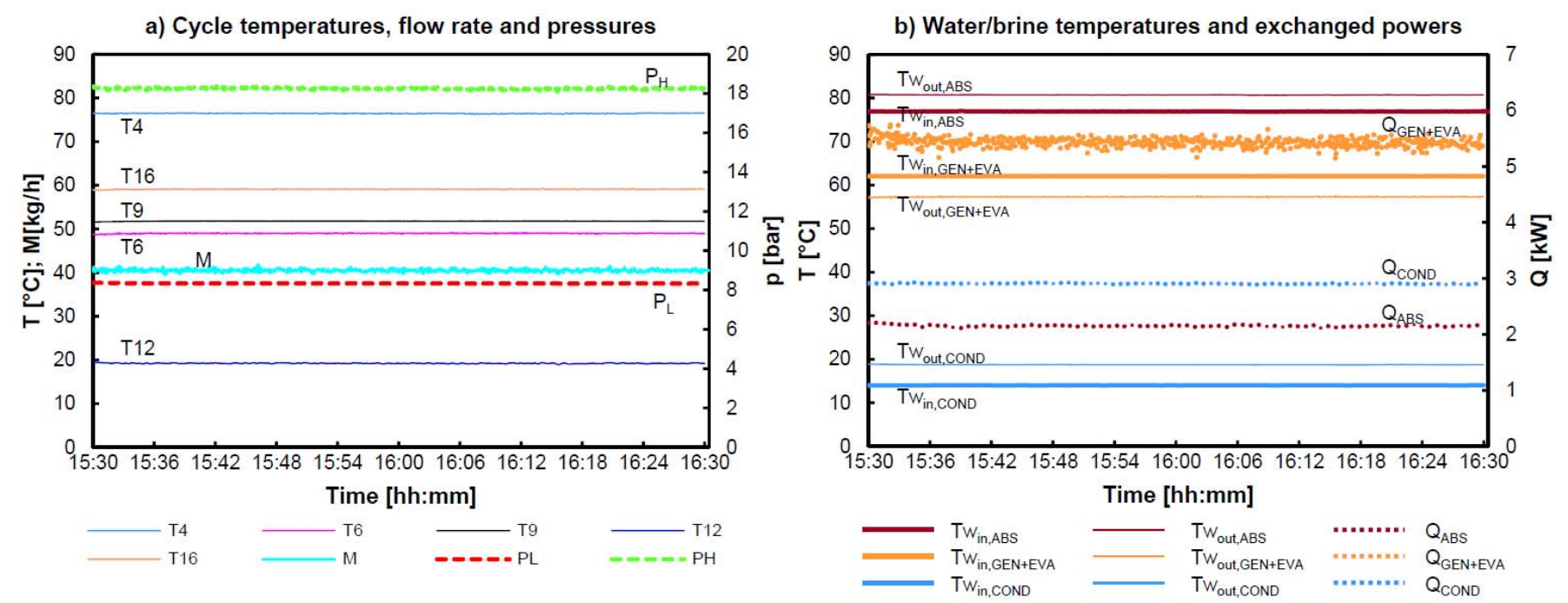

Figure 5: History of pressures, heat duties and main temperatures over a one-hour period to assess the cycle stability

\subsection{Response to step variation}

The machine proved able to react well to step variations, providing a fast and stable transient behaviour.

In Figure 6, a representative case is reported. At 15:20, the water temperature at absorber inlet (thick red continuous line in Figure $6 \mathrm{~b}$ ) is risen from $72{ }^{\circ} \mathrm{C}$ to $77^{\circ} \mathrm{C}$ in a cycle having a generator water inlet temperature of $62{ }^{\circ} \mathrm{C}$ and a brine temperature at condenser inlet of $14{ }^{\circ} \mathrm{C}$.

The high pressure level in the absorber $\left(p_{H}\right)$ is the first variable to increase, as a direct consequence of the higher temperature. This increases the pressure difference across the restrictor, and therefore the mass flow rate of the rich solution. In the following minutes, as the temperature of the rich solution leaving the absorber (T4) also starts to feel the increase, its density lowers and, thus, the mass flow rate decreases. The formation of a few bubbles in the pipes (oscillations of $\mathrm{M}$, mass flow rate of the rich solution) causes the flow rate to decrease more than necessary. This causes an initial decrease in the refrigerant flow rate (which can be seen by the decrease of its temperature T12, as well as of $Q_{C O N D}$ and $\left.Q_{G E N+E V A}\right)$.

With a second oscillation, the mass flow rate stabilizes after 10 minutes on the final value. 
Working in less favourable conditions, the useful effect decreases, while condenser temperatures and heat duty are almost unaffected. A new stability on the useful effect is reached within ten minutes, when the average QABS of the following 5 minutes differ by only $0.6 \%$ from the value in the next five minutes.
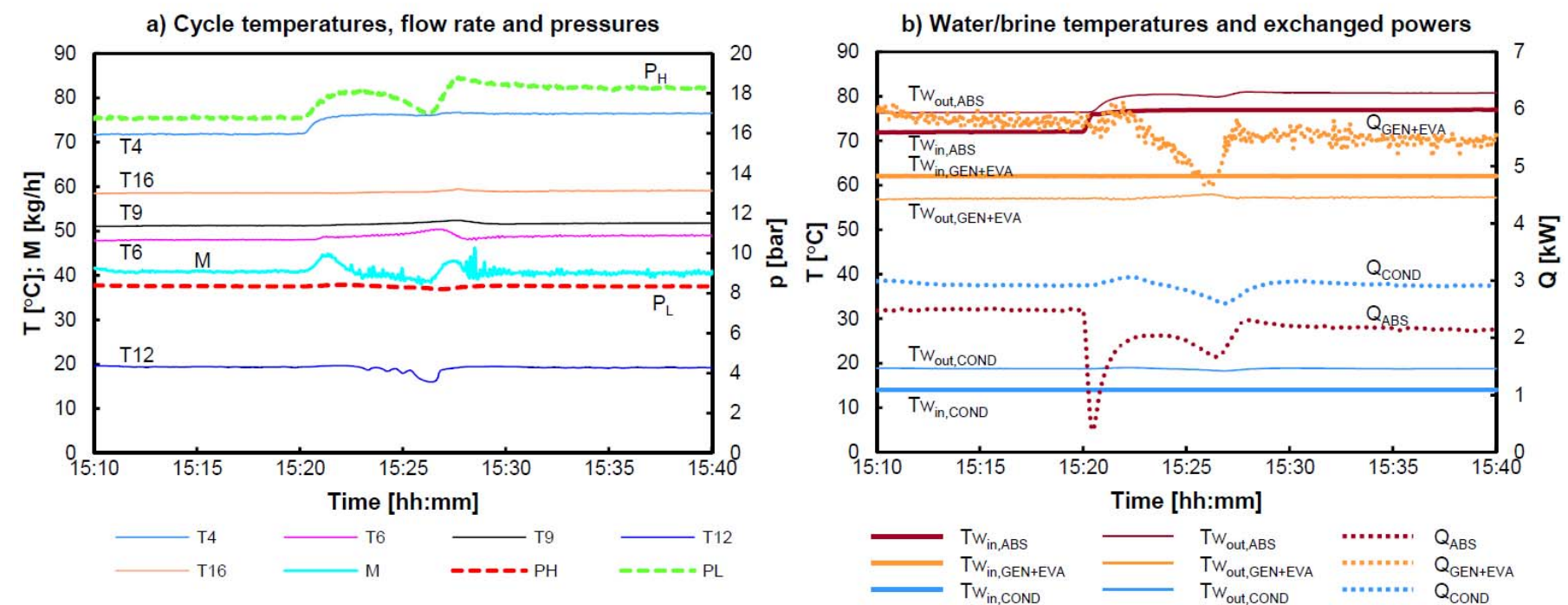

Figure 6: response to step variation. $T w_{i n, A B S}$ is increased by $5{ }^{\circ} \mathrm{C}$

\section{Performances}

\subsection{Influence of absorber temperature}

Results plotted in Figure 7 show how both heat duty and thermal COP decrease with the required thermal lift, therefore at increasing $T w_{i n_{-} A B S}$ and constant $T w_{i n, G E N}$. In the explored range, the decrease is almost constant. A cut-off point, above which performances rapidly drop, will eventually be reached at even higher $T w_{i n, A B S}$. Such temperature levels require pressurized water circuits and were therefore not tested. 

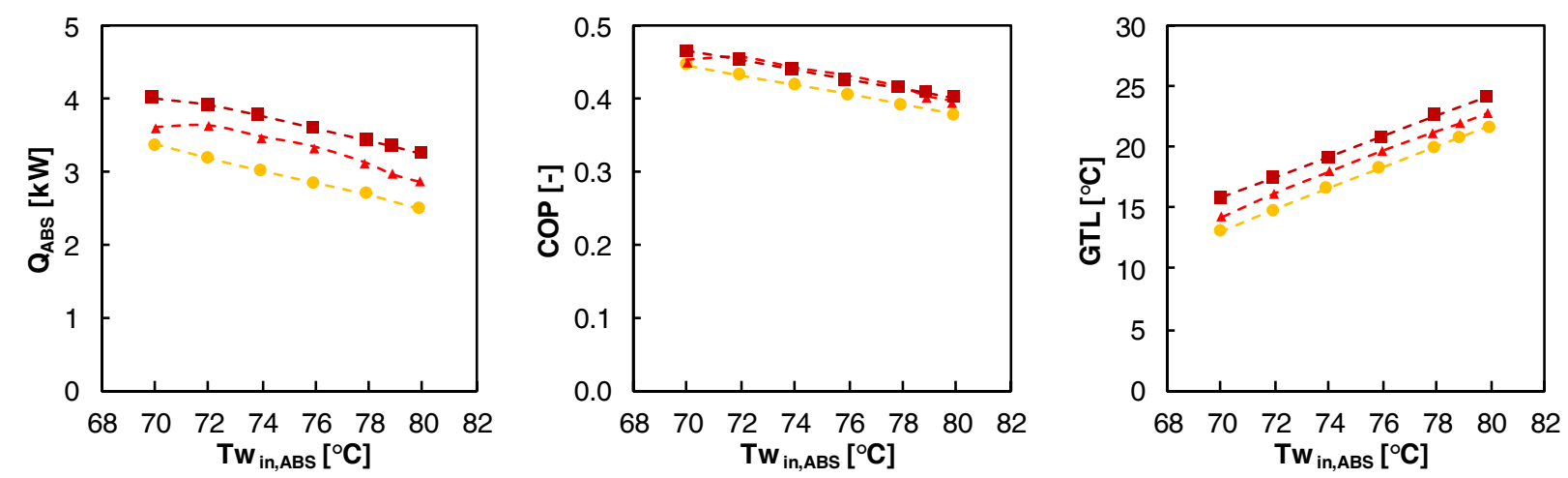

$\mathrm{TW}_{\text {in,GEN+EVA }}-\rightarrow--60^{\circ} \mathrm{C}-\rightarrow--62^{\circ} \mathrm{C}-\rightarrow--64^{\circ} \mathrm{C}$

Figure 7: performances (heat delivered at the absorber, COP and GTL) variation at different $T w_{i n, A B S}$ and $T w_{i n, G E N+E V A}$. Data were obtained at $T w_{\text {in, } C O N D}=10^{\circ}$.

An interpretation of the cycle behaviour is given by Figure 8, where the relevant state-points are represented in a pressure-temperature-concentration (PTX) diagram. Only saturated liquid points can be displayed on such a chart. Point 1, 4 and 12 are respectively the state points at generator, absorber (solution) and condenser outlets. They are with good approximation in the state of saturated liquid, and are therefore represented with their measured temperature and pressure. Point 8 is the liquid inlet to the generator, obtained from separating the two-phase outlet of the restrictor, so it is also an equilibrium point. Point $\mathrm{M}$ is a non-measured point, representing the adiabatic mixing point on top of the absorber, which is also the theoretical limit to $T w_{\text {out }, A B S}$.

Point 14 (evaporator inlet) is normally at least $5{ }^{\circ} \mathrm{C}$ subcooled, so point $14 \mathrm{~B}$ is shown. It is a point internal to the evaporator, at the actual concentration and pressure but at bubble point. The refrigerant line goes from 12 (condenser outlet) to 14B (bubble point in the evaporator). Rich solution flows from 4 to 8 through the restrictor, while poor solution is pumped from point 1 to the high pressure level on top of the absorber (M). 


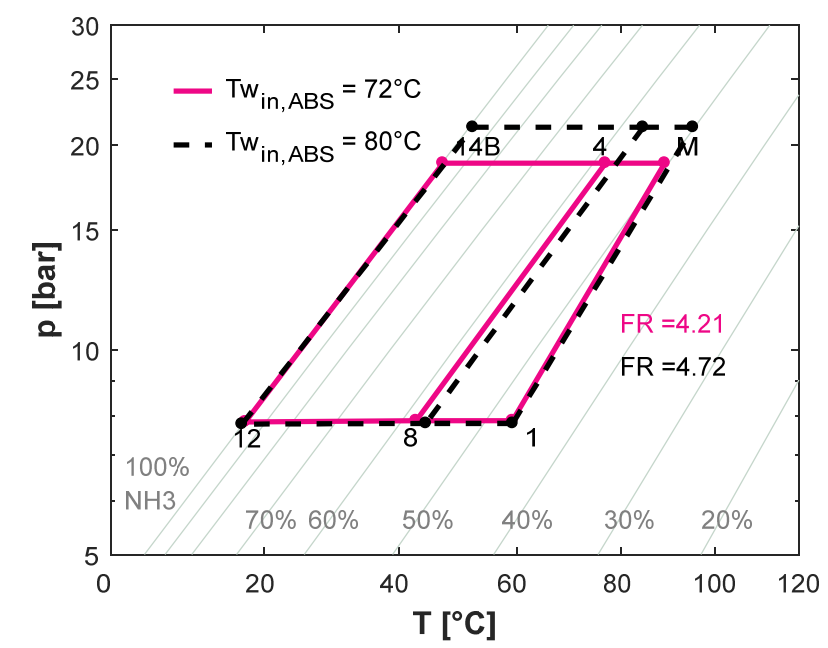

Figure 8: comparison of two representative tests with different absorber temperature on a pressure-temperature concentration diagram. Data were obtained at $T w_{i n, G E N+E V A}=60^{\circ} \mathrm{C} ; T w_{i n, C O N D}=10^{\circ} \mathrm{C}$

Plotting those point for two tests in the same condition, but at different absorber temperatures (inlet temperature $72{ }^{\circ} \mathrm{C}$ and $80{ }^{\circ} \mathrm{C}$ respectively), shows how the poor solution concentration (1), as well as the low pressure level $p_{L}$, being determined by the generator and the condenser, are almost unvaried: the poor solution concentration (1) goes from 0.471 to 0.469 . The high pressure increases, as well as the temperature of the absorber outlet (4). Such increase in T4 causes the ammonia concentration in the rich solution (8) to decrease from 0.581 to 0.566 , resulting in a decrease in the refrigerant flow rate, and a consequent increase in the flow ratio. Such a flow ratio is particularly significant: indeed, COP exhibits a linear trend with the flow ratio value.

The temperature difference between point 4 and $M$ decreases, indicating that less heat can be delivered by absorption. Nevertheless, it is interesting to note how point $\mathrm{M}$ moves to the right at higher absorber temperature, meaning the theoretical limit to the outlet temperature also shifts up. Such a limit is normally quite far from the outlet temperature achieved in these tests (which can be derived from GTL in Figure 7). For example, for the higher absorber temperature line, point M lies at $95^{\circ} \mathrm{C}$, while a GTL of $22^{\circ} \mathrm{C}$ was achieved in the test, meaning that the coolant outlet temperature was $82^{\circ} \mathrm{C}$. Thus, there is a certain room for improving the GTL by simply lowering the water flow rate. 


\subsection{Influence of generator temperature}

Figure 7 also shows the trends for three different generator temperatures. Of course, the higher $T w_{\text {in,GEN }}$, the more heat can be taken up by the machine and released at high temperature. Nevertheless, the increase of heat duty is less evident at higher temperatures, where little or no effect on thermal COP is recorded.

The pressure-temperature-concentration diagram in Figure 9 shows how the cycle is affected by an increase of the generator temperature. The first effect is that the low pressure level, as well as the temperature of the solution output from the generator, increases. The result is a poorer solution outlet from the generator. With a poorer solution and no variation in the temperature of the absorber coolant, the absorber delivers more heat, and the solution outlet temperature in 4 is higher, with little variation in concentration but a rise in the high pressure level $p_{H}$. The new cycle therefore has a lower circulation ratio, higher COP and delivered heat at the absorber.

The adiabatic mixing point also shifts to the right, indicating that the maximum outlet temperature of the coolant also increases.

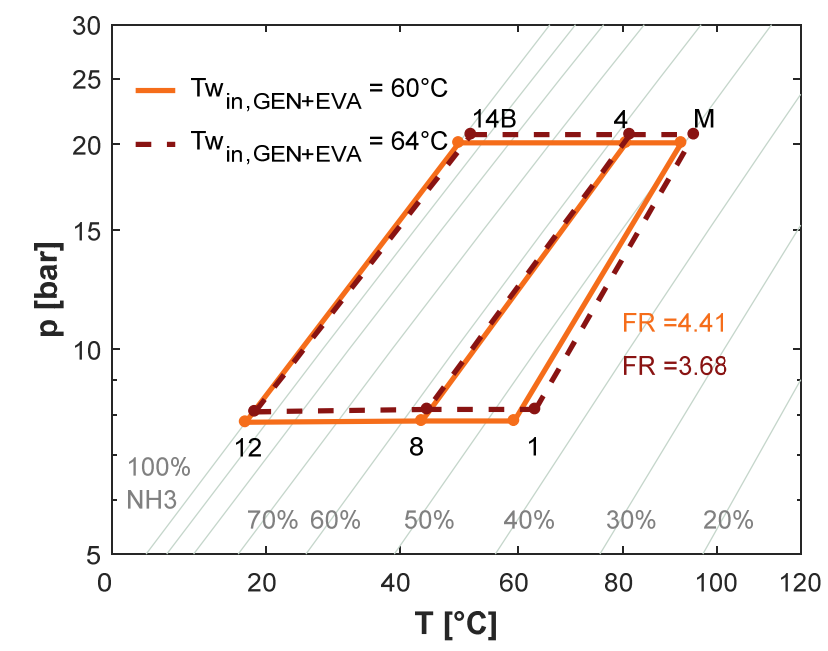

Figure 9: comparison of two representative tests with different generator temperature on a pressure-temperatureconcentration diagram. Data were obtained at $T w_{i n, A B S}=76^{\circ} \mathrm{C} ; \mathrm{T} w_{i n, C O N D}=10^{\circ} \mathrm{C}$ 


\subsection{Influence of condenser temperature}

As shown in Figure 10, the increase of the delivered heat duty by lowering the condenser temperature is particularly strong. As in the generator, the impact decreases in more favourable conditions, i.e. at lower temperature. At the same time, COP variations are very small: only the lines obtained at $14{ }^{\circ} \mathrm{C}$ and $16{ }^{\circ} \mathrm{C} T w_{\text {in_COND }}$ begin to deviate from the others.
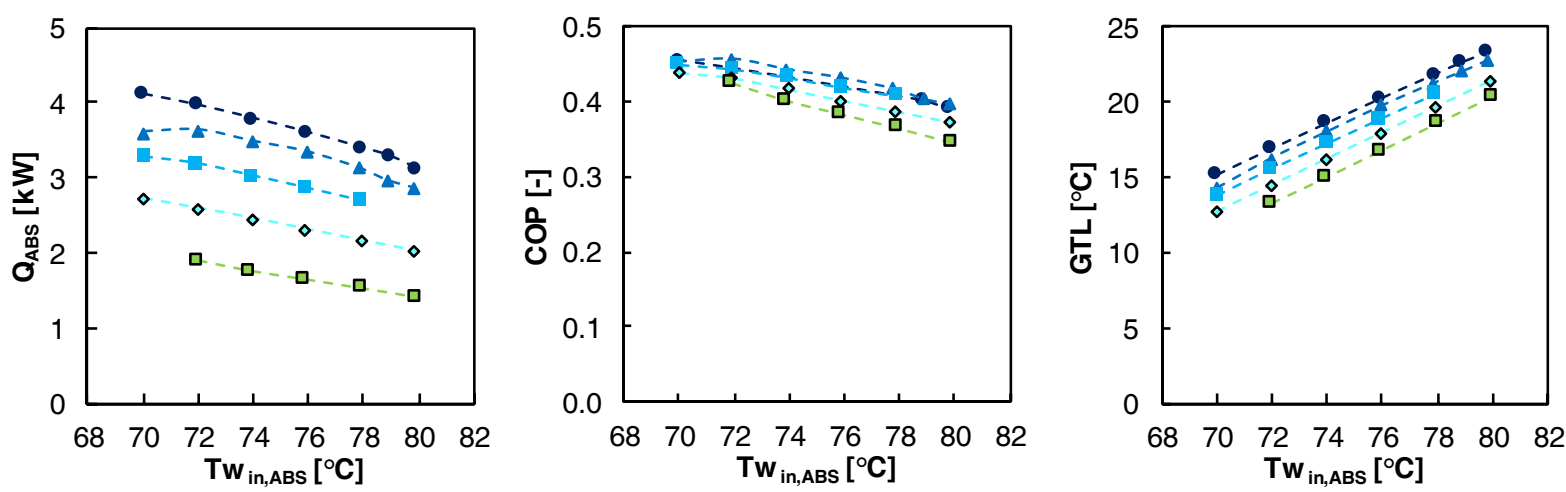

$$
\mathrm{Tw}_{\text {in, COND }} \quad-\rightarrow-8^{\circ} \mathrm{C} \quad-\rightarrow--10^{\circ} \mathrm{C} \quad----12^{\circ} \mathrm{C} \quad-\diamond-14^{\circ} \mathrm{C} \quad--\square-16^{\circ} \mathrm{C}
$$

Figure 10: performances (heat delivered at the absorber, COP and GTL) variation at different $T w_{\text {in, } A B S}$ and $T w_{\text {in,COND. Data }}$ were obtained at $T w_{i n, G E N}=62^{\circ} \mathrm{C}$.

The pressure-temperature-concentration diagram in Figure 11 provides a deeper insight of the changes in the cycle when the condenser temperature is modified.

Increasing the condenser coolant temperature causes the outlet temperature of the refrigerant outlet (point 12) to increase. The refrigerant concentration is not affected, so the low pressure level rises. The temperature of the generator outlet, being driven by the input heat temperature, does not significantly change: at higher $p_{L}$, this means having a higher concentration of poor solution in point 1 . The mass flow rate of the refrigerant therefore decreases. To keep the rich solution concentration constant, the rich solution flow rate would need to change accordingly, but the machine has a non-variable restrictor. So, the variation of the rich solution mass flow rate is driven by the characteristic curve of the restrictor as a function of inlet pressure and sub-cooling. As a consequence of the higher condenser temperature, the restrictor flow rate only decreases slightly. The result is a poorer rich solution leaving the absorber, and a shift of $p_{H}$ to a lower level. 
The combined effect of higher $p_{L}$ and lower $p_{H}$ doubles the circulation ratio and reduces the heat delivered at the absorber. Also, the horizontal distance between points 4 and $\mathrm{M}$ decreases: the fraction of the absorption process carried out in the adiabatic mixing phase therefore increases by rising the condenser temperature.

Analysing the cycle behaviour with increasing condenser temperature suggests that a variable restrictor, to introduce a higher pressure drop as the condenser temperature increases, could limit the loss of efficiency at higher sink temperatures.

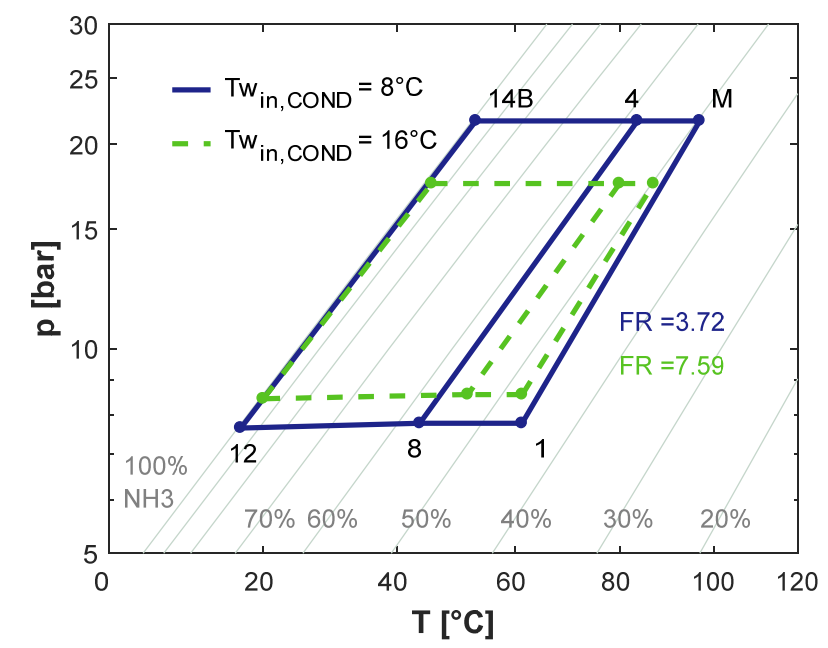

Figure 11: comparison of two representative tests with different condenser temperature on a pressure-temperature concentration diagram. Data were obtained at $T w_{i n, G E N}=62^{\circ} \mathrm{C} ; T w_{i n, A B S}=78^{\circ} \mathrm{C}$.

\subsection{Relation between flow ratio and COP}

As described in the previous paragraphs, variations of the external conditions cause changes in the flow ratio. As pictured in Figure 12, an increase of the gross temperature lift induces a linear increase in the flow ratio value. As conditions become less favourable, e.g. at higher condenser temperature or reduced generator temperature, the line shifts upwards and becomes steeper.

As a consequence, the electrical coefficient of performance

$$
E C O P=\frac{Q_{A B S}}{W}
$$


also decreases with a strong dependence from GTL, which is not only due to an increased pump consumption but also to the decrease of the absorber heat duty. Therefore, the numerator of ECOP decreases while the denominator increases.

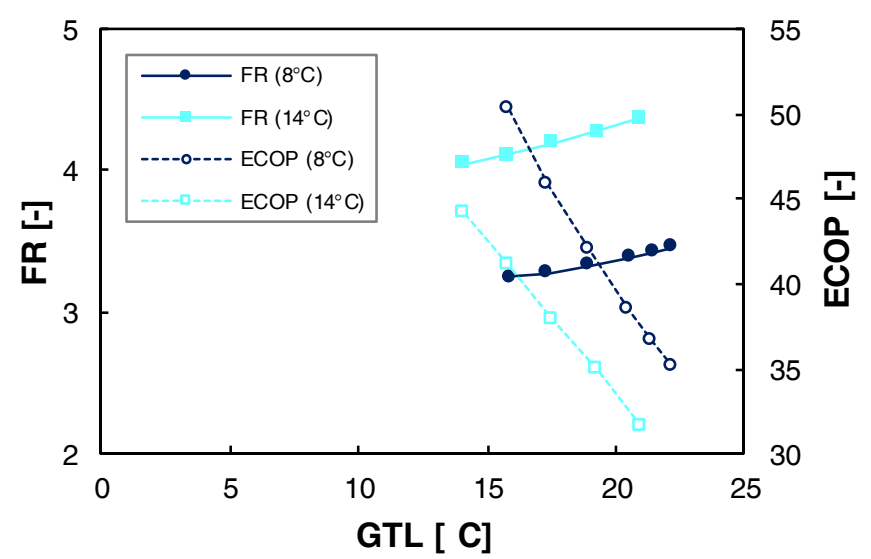
$64^{\circ} \mathrm{C}$.

Figure 12: FR and ECOP trends with gross temperature lift for two condenser temperatures. Data were obtained at $T w_{\text {in,GEN }}=$

\subsection{Performance comparison with literature data}

Performances are finally compared with other available experimental data.

A rigorous comparison between fluids or machines would require testing under the same set of operating conditions, because the combination of all the three external temperature levels is crucial in determining the machine behaviour. Since this is not possible with most of the available data, the comparison was carried out on the basis of a non-dimensional temperature difference. In Figure 13, COP is plotted against the ratio between internal achieved temperature lift and driving temperature difference:

$$
\theta=\frac{T_{\text {out }, A B S}-T_{\text {out }, G E N}}{T_{\text {out }, G E N}-T_{\text {out }, C O N D}}
$$

This allows a first comparison, whose results need to be taken carefully, both due to the linear structure of the indicator and to different assumptions in the various works. For example, the refrigerant heat exchanger (RHE) is only used in the present work. 
In any case, the comparison suggests that the performances of our ammonia-water prototype are at least comparable and possibly better than those achieved by other real machines.

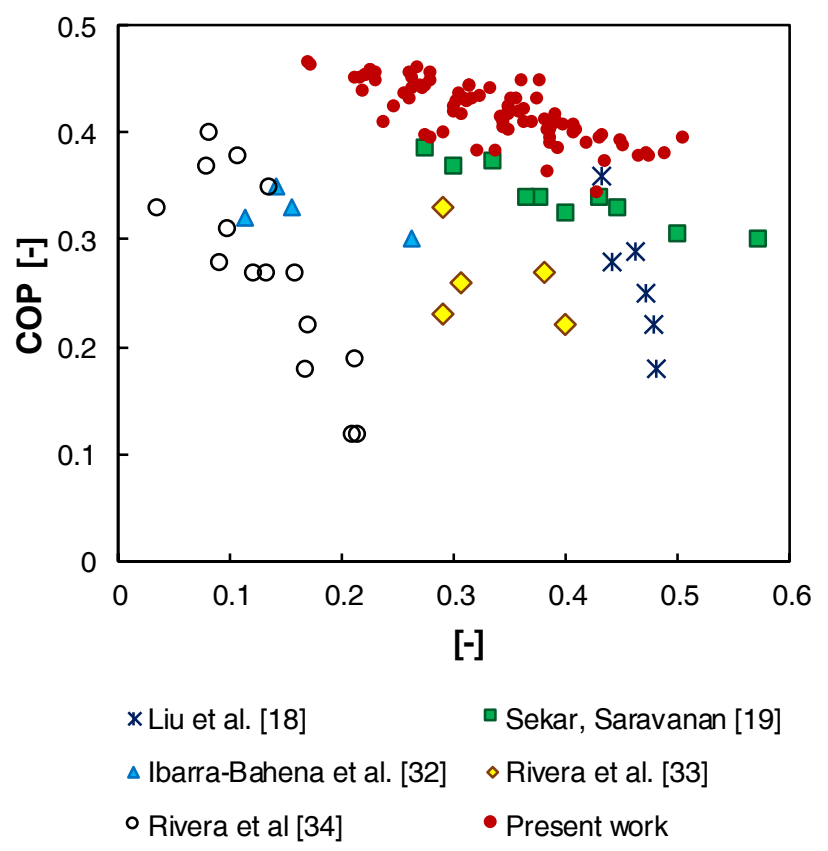

Figure 13: COP of various single-stage absorption heat transformer as reported in literature. Ibarra-Bahena et al. [32] used water-Carroll; Rivera et al. [34] used water-LiBr for five points, and subsequently 1-octanol and 2-ethyl-1-hexanol as additives for five points each. All other data were obtained using water-LiBr. Whenever available, COP based on the actual heat duties delivered to the external fluids was used

\section{Conclusions}

The built prototype has achieved reliable and stable operation. With waste heat temperatures ranging from $60{ }^{\circ} \mathrm{C}$ to $64{ }^{\circ} \mathrm{C}$ and cold sink at $8-16{ }^{\circ} \mathrm{C}$ (suitable for dry-cooling in winter), GTL up to $25^{\circ} \mathrm{C}$ were obtained and thermal $\mathrm{COP}$ was in the range $0.35 \div 0.47$. Compared to other experimental studies with different operating fluids, those results are promising. Higher temperature lifts $\left(30-35{ }^{\circ} \mathrm{C}\right)$ can be achieved by simply lowering the coolant flow rate, since the adiabatic mixing temperature, representing the theoretical limit to the outlet coolant temperature is normally above $90^{\circ} \mathrm{C}$. 
Throughout the testing campaign, the flow ratio varied between 3.3 and 8 , while electric consumption stayed always below $100 \mathrm{~W}$, corresponding to an ECOP ranging from 18 to 50, with an average value of 35 .

The variation of the cycle performances and behaviour with the three operating temperature levels has been explored.

The delivered heat undergoes significant changes with the operating conditions. In the investigated range, approximately $0.25 \mathrm{~kW}$ are gained per $\mathrm{K}$ of temperature increase at the generator and lost per $\mathrm{K}$ of temperature increase at the condenser, while less than $0.1 \mathrm{~kW}$ is lost per $\mathrm{K}$ of temperature increase at the absorber. Such a variation is anyway more moderate in favourable conditions and more evident in more severe conditions, closer to the cut-off point.

For a wide temperature range, $\mathrm{COP}$ is quite insensitive to the external temperatures, though changes become more evident in more critical conditions. In the investigated range, the condenser temperature plays the most relevant role in affecting both heat duty and efficiency. This behaviour implies that the use of a water-ammonia heat transformer for heating purposes in winter becomes particularly interesting, because the load and performance curves would act accordingly. Additionally, the analysis of the experimental results suggests the possibility to partially tune the cycle operation with a variable restrictor.

\section{Nomenclature}

M Mass flow rate of rich solution $[\mathrm{kg} / \mathrm{h}]$

$p_{H} \quad$ Cycle high pressure level, absolute [bar]

$p_{L} \quad$ Cycle low pressure level, absolute [bar]

Q Exchanged thermal power $[\mathrm{kW}]$

$\mathrm{T} \quad$ Temperature of the working fluid $\left[{ }^{\circ} \mathrm{C}\right]$

Tw Temperature of water or brine in the external circuits $\left[{ }^{\circ} \mathrm{C}\right]$ 
Volumetric flow rate $\left[\mathrm{m}^{3} / \mathrm{h}\right]$

W

Electrical power of the solution and refrigerant pumps [W]

$\rho$

Density $\left[\mathrm{kg} / \mathrm{m}^{3}\right]$

$\theta$

Solution temperature difference ratio: $\theta=\frac{T_{\text {out }, A B S^{-} T_{\text {out }, G E N}}}{T_{\text {out }, G E N}-T_{\text {out }, C O N D}}=\frac{T 4-T 1}{T 1-T 12}[-]$

Subscripts

ABS Relative to the absorber

COND Relative to the condenser

EVA Relative to the evaporator

GEN Relative to the generator

GEN+EVA Relative to the hydraulic circuit serving the generator and evaporator in series in Inlet

out Outlet

Acronyms and abbreviations

ABS Absorber

COP Coefficient of thermal performance: $\operatorname{COP}=\frac{Q_{A B S}}{Q_{G E N+E V A}}[-]$

COND Condenser

FR $\quad$ Flow ratio: $F R=\frac{M 1}{M 12}=\frac{C 1}{C 4-C 1}[-]$

ECOP Coefficient of electric performance: $E C O P=\frac{Q_{A B S}}{W}[-]$

EVA Evaporator

GEN Generator

GTL Gross Temperature Lift: $G T L=T w_{o u t, A B S}-T w_{\text {in,GEN }+E V A}\left[{ }^{\circ} \mathrm{C}\right]$

RHE Refrigerant Heat Exchanger 
SEP

Separator

SHX

Solution Heat eXchanger

\section{Acknowledgments}

This work was partly funded by Regione Lombardia as an activity of the project "Triboulet".

\section{REFERENCES}

[1] B. Inc, Waste Heat Recovery: Technology Opportunities in the US Industry, Waste Heat Recover. Technol. Oppor. US Ind., pp. 1-112, 2008.

[2] D. Connolly, S. Nielsen, U. Persson, Heat Roadmap Europe 2050. Second pre-study for the EU27, 2013. doi:10.1017/CBO9781107415324.004.

[3] Eurostat, Energy, transport and environment indicators, 2014. doi:10.2785/56625.

[4] C. Forman, I.K. Muritala, R. Pardemann, B. Meyer, Estimating the global waste heat potential, Renew. Sustain. Energy Rev. 57 (2016) 1568-1579. doi:10.1016/j.rser.2015.12.192.

[5] Brückner, S. Liu, L. Miró, M. Radspieler, L.F. Cabeza, E. Lävemann, Industrial waste heat recovery technologies: An economic analysis of heat transformation technologies, Appl. Energy. 151 (2015) 157-167. doi:10.1016/j.apenergy.2015.01.147.

[6] J. Zhang, H. Zhang, K. Yang, F. Yang, Z. Wang, G. Zhao, H. Liu, E. Wang, B. Yao, Performance analysis of regenerative organic Rankine cycle (RORC) using the pure working fluid and the zeotropic mixture over the whole operating range of a diesel engine, Energy Convers. Manag. 84 (2014) 282-294. doi:10.1016/j.enconman.2014.04.036.

[7] S. Quoilin, M. Van Den Broek, S. Declaye, P. Dewallef, V. Lemort, Techno-economic survey of organic rankine cycle (ORC) systems, Renew. Sustain. Energy Rev. 22 (2013) 168-186. doi:10.1016/j.rser.2013.01.028.

[8] H. Gadd, S. Werner, Achieving low return temperatures from district heating substations, Appl. Energy. 136 (2014) 59-67. doi:10.1016/j.apenergy.2014.09.022. 
[9] T. Ommen, W.B. Markussen, B. Elmegaard, Lowering district heating temperatures - Impact to system performance in current and future Danish energy scenarios, Energy. 94 (2016) 273291. doi:10.1016/j.energy.2015.10.063.

[10] Z. Zhao, X. Zhang, X. Ma, Thermodynamic performance of a double-effect absorption heattransformer using TFE/E181 as the working fluid, Appl. Energy. 82 (2005) 107-116. doi:10.1016/j.apenergy.2004.10.012.

[11] J.C. Romero, R.J., Sotsil Silva - Sotelo, First double stage heat transformers (Dsht) in latinamerica, Chem. Eng. Trans. 19 (2010) 149-156. doi:10.3303/CET1019025.

[12] P. Donnellan, E. Byrne, K. Cronin, Internal energy and exergy recovery in high temperature application absorption heat transformers, Appl. Therm. Eng. 56 (2013) 1-10. doi:10.1016/j.applthermaleng.2013.03.027.

[13] W. Rivera, R. Best, M.J. Cardoso, R.J. Romero, A review of absorption heat transformers, Appl. Therm. Eng. 91 (2015) 654-670. doi:10.1016/j.applthermaleng.2015.08.021.

[14] K. Abrahamsson, A. Gidner, Å Jernqvist, Design and experimental performance evaluation of an absorption heat transformer with self-circulation, Heat Recover. Syst. CHP. 15 (1995) 257-272. doi:10.1016/0890-4332(95)90010-1.

[15] K. Stephan, M. Schmitt, D. Hebecker, T. Bergmann, Dynamics of a heat transformer working with the mixture NaOH-H2O, Int. J. Refrig. 20 (1997) 483-495. doi:10.1016/S01407007(97)00047-9.

[16] X. Ma, J. Chen, S. Li, Q. Sha, A. Liang, W. Li, J. Zhang, G. Zheng, Z. Feng, Application of absorption heat transformer to recover waste heat from a synthetic rubber plant, Appl. Therm. Eng. 23 (2003) 797-806. doi:10.1016/S1359-4311(03)00011-5.

[17] C. Mostofizadeh, C. Kulick, Use of a new type of heat transformer in process industry, Appl. Therm. Eng. 18 (1998) 857-874. doi:10.1016/S1359-4311(97)00115-4. 
[18] F. Liu, J. Sui, H. Liu, H. Jin, Experimental studies on a direct-steam-generation absorption heat transformer built with vertical falling-film heat exchangers, Exp. Therm. Fluid Sci. 83 (2017) 9-18. doi:10.1016/j.expthermflusci.2016.11.033.

[19] S. Sekar, R. Saravanan, Experimental studies on absorption heat transformer coupled distillation system, DES. 274 (2011) 292-301. doi:10.1016/j.desal.2011.01.064.

[20] R.M. Barragán, C.L. Heard, V.M. Arellano, R. Best, F.A. Holland, Water / Calcium Chloride System in a Heat, Int. J. Energy Res. 20 (1996) 651-661.

[21] P. Donnellan, K. Cronin, E. Byrne, Recycling waste heat energy using vapour absorption heat transformers: A review, Renew. Sustain. Energy Rev. 42 (2015) 1290-1304. doi:10.1016/j.rser.2014.11.002.

[22] K. Parham, M. Khamooshi, D.B.K. Tematio, M. Yari, U. Atikol, Absorption heat transformers - A comprehensive review, Renew. Sustain. Energy Rev. 34 (2014) 430-452. doi:10.1016/j.rser.2014.03.036.

[23] R. Best, W. Rivera, Thermodynamic design data for absorption heat transformers. Part six: operating on water-Carrol, Heat Recovery Syst. CHP 14 (4) (1994) 427-436.

[24] M. Bourouis, A. Coronas, R. Romero, J. Siqueiros, Purification of seawater using absorption heat transformers with water- $(\mathrm{LiBr}+\mathrm{LiI}+\mathrm{LiNO} 3+\mathrm{LiCl})$ and low temperature heat sources, Desalination. 166 (2004) 209-214. doi:10.1016/j.desal.2004.06.075.

[25] F. Ziegler, Recent developments and future prospects of sorption heat pump systems, Int. J. Therm. Sci. 38 (1999) 191-208. doi:10.1016/S1290-0729(99)80083-0.

[26] E. Kurem, I. Horuz, A comparison between ammonia-water and water-lithium bromide solutions in absorption heat transformers, Int. Commun. Heat Mass Transf. 28 (2001) 427438.

[27] K.E. Herold, R. Radermacher, S.A. Klein, Absorption Chillers and Heat Pumps, CRC Press, Boca Raton, 1996 
[28] E.C. McKelvy, A. Isaacs, Causes and prevention of the formation of noncondensable gases in ammonia absorption refrigeration machines, Technol. Pap. Bur. Stand. (1920).

[29] R. Best, M.A.R. Eisa, F.A. Holland, Thermodynamic design data for absorption heat transformers-III. Operating on ammonia-water, Heat Recover. Syst. CHP. 7 (1987) 259-272.

[30] K. V. Eisberg, "Absorption refrigeration systems having solution-cooled absorbers," $3423951,1969$.

[31] H. Moser, G. Zotter, O. Kotenko, R. Rieberer, The formation of non-condensable gases in ammonia/water absorption heat pumps made of stainless steel - literature review and experimental investigation, Proceedings of the 4th IIR International Conference on Ammonia Refrigeration Technology, Ohrid, April 14-16, 2011.

[32] J. Ibarra-Bahena, R.J. Romero, L. Velazquez-Avelar, C. V. Valdez-Morales, Y.R. GalindoLuna, Experimental thermodynamic evaluation for a single stage heat transformer prototype build with commercial PHEs, Appl. Therm. Eng. $75 \quad$ (2015) 1262-1270. doi:10.1016/j.applthermaleng.2014.05.018.

[33] W. Rivera, A. Huicochea, H. Martínez, J. Siqueiros, D. Juárez, E. Cadenas, Exergy analysis of an experimental heat transformer for water purification, Energy. 36 (2011) 320-327. doi:10.1016/j.energy.2010.10.036.

[34] W. Rivera, H. Martínez, J. Cerezo, R.J. Romero, M.J. Cardoso, Exergy analysis of an experimental single-stage heat transformer operating with single water/lithium bromide and using additives (1-octanol and 2-ethyl-1-hexanol), Appl. Therm. Eng. 31 (2011) 3525-3532. doi:10.1016/j.applthermaleng.2011.07.006. 